\title{
How to Build Prevention for the Elderly and Disabled before Natural Disasters? The Added Social Value of Voluntary Organizations in Europe
}

\author{
Andrea Volterrani \\ Department of Enterprise Engineering, University of Rome Tor Vergata, Italy
}

Copyright $\subseteq 2016$ by authors, all rights reserved. Authors agree that this article remains permanently open access under the terms of the Creative Commons Attribution License 4.0 International License

\begin{abstract}
In disaster situations, such as floods or earthquakes, the elderly and people with disabilities are particularly vulnerable and require additional attention. However, they are often neglected in existing municipal disaster emergency plans, particularly when such people live alone instead of in a care institution as their location is often undetermined in disaster situations or the information exists (e.g. if the people receive social services or if neighbours are aware of people in need in their vicinity) but is not structured in a way that is usable for civil protection emergencies. Up-to-date information for helpers and a community that is aware of this particular challenge for disaster relief can alleviate this problem. The paper presents the first results of the research action carried out by a joint partnership (universities/Italian, German and Danish voluntary organizations) highlighting: 1) which aspects are relevant for identifying the condition of vulnerability of the elderly and disabled; 2) how to develop a system for vulnerable people in integrated risk management mechanisms through local networks and volunteers; and 3) what is the added social value of volunteering in prevention and support for the elderly and disabled and the contribution to strengthening the resilience of local communities.
\end{abstract}

Keywords Vulnerability, Natural Disaster, Social Added Value, Voluntary Organizations

\section{In Search of Marginal Resilience}

In this paper we present the results of the research carried out in four local communities based in three European countries (two in Italy, one in Germany and one in Denmark) with very different daily life cultures ${ }^{1}$. The communities involved were hit by different types of natural calamities, and they also distinguish themselves by the presence or absence of detailed emergency plans involving vulnerable people and by the major or minor involvement of stakeholders (public and nonprofit organizations).

The above-mentioned differences were fundamental to the research because they allowed for the clearer identification of the common aspect necessary for coming up with a prevention strategy at a European level and the specific aspects and characteristics of each context in order to come up with an original strategy for each community.

\subsection{Research Objectives}

There were three main research objectives. The first was to decide which aspects were relevant in order to identify the condition of vulnerability of the elderly and disabled individuals. The second was how to develop a system for vulnerable people in integrated risk management mechanisms through local networks and volunteers. The third was the added social value of volunteering in prevention and support for the elderly and disabled people, and the contribution to strengthening the resilience of local communities.

The vulnerable situation of the elderly and disabled in a local community is critical for understanding the resilience of a community.

In international literature and the theoretical models of measuring resilience $(1 ; 2 ; 3)$, it is not possible to arrive at this level of detail in the construction of the indicators. Vulnerable populations are often cited without considering the merits of the specific characteristics of each individual.

The cross-cutting theme was, instead, the identification of the vulnerable situations of elderly and disabled people with as much detail as possible in order to increase the resilience of communities through the integration of risk management. 


\subsection{Features of Marginal Resilience}

It was then that the reconstruction of the resilience could be called "marginal" because it related to population segments that are traditionally considered marginal from the center of the territorial communities. Marginal resilience is critical if we capture the ability of a community to respond to natural disasters and, more generally, to acute crisis situations.

Marginal resilience is the ability of a local community to respond to natural disasters through the leadership of disabled people and older people (marginalized groups of the population) and the active presence of voluntary organizations.

It is an important integration of the concept of resilience because it allows for the understanding of how and how much a territorial community is able to include and, at the same time, to incorporate the public.

The leading role of the disabled and elderly (where this is possible due to personal autonomy) change the idea that civil protection interventions should be centralized and only dropped from the above.

In addition, voluntary organizations play a vital role in the link between marginal population groups and the rest of the local community, even before natural disasters contribute to an increased awareness and prevention.

\section{Concepts and Methods for the Identification of Vulnerability}

\subsection{Ethics of Research}

It is important to stress that the research was carried out following three basic principles:

- Participation. Research is a research-action where the scientific part is secondary to the role of the voluntary organizations involved.

- Sharing of content and tools. The contents of the research and tools are shared (and built together):

- using a mix of quantitative tools (questionnaire, enhancing administrative files, $\mathrm{Eu}$ Silc, local authorities' administrative records, and local volunteer organizations' records) and qualitative tools (in-depth interviews, participant observation, volunteer diaries, social landscape, etc.).

- Involvement of researchers and volunteers for the best definition of instruments for specific local communities.

- Ethics of results. The results will be used respecting the ethics, accountability and privacy of the people involved.

\subsection{The Concept of Vulnerability}

Our approach starts from the idea that vulnerability is an intermediate condition between the area of social inclusion and the area of social exclusion.
The definition given by the French sociologist Castel (4) highlights the slow passage that can take place between the first and the second areas and which identifies the area of vulnerability.

The path of impoverishment of a potential subject may pass through life from the area of integration (insertion in a stable employment circuit and availability of solid relational supports, especially family members) to the area of disaffiliation, faced by individuals in extreme poverty (characterized by processes of decay and abandonment of self, inability to control physical space, a deep rupturing of social ties, and loss of the ability to convert assets into life opportunities). This transition occurs through micro-fractures in the experience of the subjects, both at work and at the relational level, generating situations of precariousness and fragility; it is the area of social vulnerability.

In order to identify the situation of the elderly and disabled that is useful for constructing a model of appropriate intervention during a natural disaster, we consider it important to note all three areas: inclusion, vulnerability and social exclusion.

Each area will have different characteristics from the so-called "spheres of life" that characterize the daily life of a person:
a) housing situation;
b) work situation;
c) income situation;
d) situation of social relations;
e) health status;
f) situation of the level of education; and
g) situation of the local community (degree of territorial resilience)

The following diagram (Figure 1) exemplifies our approach. The passage from social inclusion to that of social vulnerability is related to the time variable on the one hand and to the deconstruction of the spheres of life on the other.

At the junction of the situation assessment of the spheres of life and the people who interpret them, we find the degree of vulnerability.

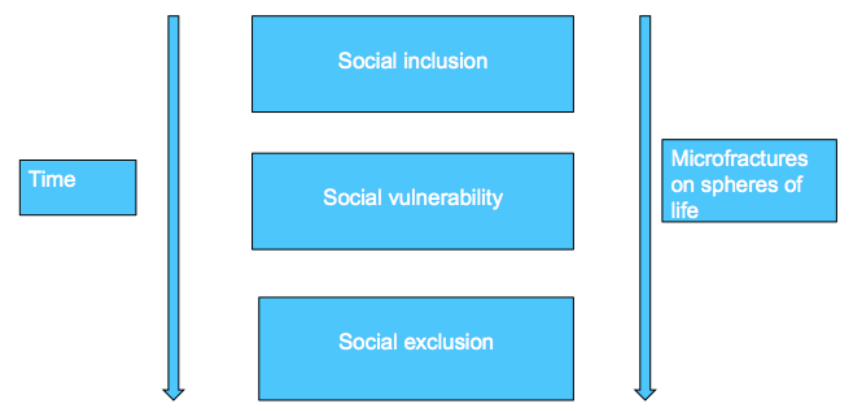

Figure 1. From inclusion to exclusion

\subsection{The Criteria for Inclusion and Exclusion}

The connection between the individual position in the 
spheres of life and the life cycle indicates the location of the disabled or elderly person in one of the three areas.

From among the spheres of life, it was decided that four were relevant to our research work: housing, income, health and social relations. For each of the areas, we identified the criteria belonging to the three areas (inclusion, vulnerability and exclusion).

For the social housing assessment, we followed the scale proposed by EU SILC, namely: a) inclusion: a house in perfect condition; b) vulnerability: a house with some signs of deterioration (such as mold on the walls, no heating, electricity or running water); and c) exclusion: a degraded house (i.e. no running water, heating or electricity; lack of toilet, and presence of a bed only).

For income, the rating scale that we used was: a) inclusion: an income above the national average and over 20,000 euros annually b) vulnerability: an income above the poverty line and less than 20,000 euros a year; and c) social exclusion: an income below the poverty line.

For health, we identified the ability of autonomy of movement: a) inclusion: the individual is able to move on their own; b) vulnerability: the individual can move slowly, either alone or accompanied; and c) exclusion: the individual cannot move on their own or is immobile.

For social relations, we identified the following rating scale: a) inclusion: the individual is a member of an association, the individual has family and friends; b) vulnerability: the individual has neighbors only; and c) exclusion: the individual lives alone and isolated.

Placement of the individual in one of the three areas (inclusion, vulnerability, or exclusion) was identified through the prevalence of specific positions within each sphere of life. A majority of positions of vulnerability required placing the individual in that area; placement within inclusion or exclusion was carried out following the same criteria. The methods of collection of the individual positions of the disabled and elderly will be outlined in the next paragraph.

\subsection{Qualitative Interviews}

Qualitative interviews were carried out by placing the disabled and elderly people in the three areas (inclusion, vulnerability, and exclusion). In interviews we analyzed the spheres of life relevant to emergency situations in case of natural disasters (see Table 1)

Social inclusion area: a person is in the area of social inclusion if they have a stable economic situation, good housing conditions, a good network of social relations, and their health conditions make them autonomous.

Social vulnerability area: a person is in the area of social vulnerability if they have at least two situations that are not stable (economic situation, housing conditions, health conditions, and social relations).

Social exclusion area: a person is in the area of social exclusion if they all of their situations are unstable (economic situation, housing conditions, health conditions, and social relations).

In an emergency situation, the areas of social vulnerability and social exclusion are most at risk.

The interviews were conducted by volunteers of the voluntary organizations involved in local action groups (see 2.5). The interview outline summarized in Table 1 was conducted using both probing techniques (5) and participant observation in the context of the lives of the disabled and elderly individuals. The analysis of the qualitative interviews was performed using the software ATLAS to identify recurrences and concepts relevant to support the position of interviewees in one of three areas (inclusion, vulnerability or exclusion).

The number of people interviewed (given the small size of the local community involved) was the totality of the disabled and $10 \%$ of the elderly population. Altogether about 3,000 elderly and 450 disabled individuals were interviewed. The average duration of the interview/visit was about one hour. 
Table 1. Scheme for qualitative interviews

\begin{tabular}{|c|c|c|c|c|c|c|c|c|c|c|c|c|c|c|c|c|}
\hline & \multicolumn{3}{|c|}{ Basic data } & \multicolumn{3}{|c|}{ Economic situation } & \multicolumn{2}{|c|}{ Housing } & \multicolumn{3}{|c|}{ Health } & \multicolumn{5}{|c|}{ Social relations } \\
\hline $\begin{array}{l}\text { Elderly } \\
\text { people }\end{array}$ & $\begin{array}{l}\text { How } \\
\text { many }\end{array}$ & $\begin{array}{l}\text { Name } \\
\text { (who are } \\
\text { they) }\end{array}$ & $\begin{array}{l}\text { Where } \\
\text { they live }\end{array}$ & Independent & $\begin{array}{l}\text { Supported } \\
\text { by the } \\
\text { state }\end{array}$ & Poverty & $\begin{array}{l}\text { Living } \\
\text { condition }\end{array}$ & $\begin{array}{c}\text { Home } \\
\text { condition }\end{array}$ & $\begin{array}{l}\text { Unable to } \\
\text { move alone }\end{array}$ & $\begin{array}{l}\text { It can } \\
\text { move } \\
\text { slowly }\end{array}$ & $\begin{array}{l}\text { Can } \\
\text { move }\end{array}$ & Alone & $\begin{array}{l}\text { Alone and } \\
\text { neighbors }\end{array}$ & Family & $\begin{array}{l}\text { Family } \\
\text { and } \\
\text { friend }\end{array}$ & $\begin{array}{l}\text { Member of } \\
\text { an } \\
\text { association }\end{array}$ \\
\hline Inclusion & & & & & & & & & & & & & & & & \\
\hline Vulnerabilit & & & & & & & & & & & & & & & & \\
\hline Exclusion & & & & & & & & & & & & & & & & \\
\hline
\end{tabular}




\subsection{The Local Action Groups}

A local action group was built in each community made up of the voluntary organizations involved in the project.

Firstly, the local action group was responsible for conducting the qualitative interviews of the elderly and disabled. To accomplish this, the group formed about fifteen volunteers for each community involved in the conduct of qualitative interviews. Secondly, the local action groups accompanied the analysis of the results to get a more in-depth knowledge of the situations of vulnerability and social exclusion in their community. Finally, the local action groups built a dynamic database with the information needed to carry out prevention and intervention of civil protection. An important result of the involvement of voluntary organizations has been the construction of new social relationships in the community and the multiplication of existing ones (see 4).

\subsection{Other Tools and Instruments for Research}

The choice of local communities was made by taking into account a population size of between 6,000 and 15,000 inhabitants.

In addition to the tools that were used to identify the personal situation of the individual, the research provides other tools for evaluating the data available to the local communities and the use that is made of it. The first is the presence of an emergency plan for people with disabilities and elderly people with some vulnerability, which is essential. It is also important to understand the method used to identify the people with disabilities: if they have only been listed; if they have been identified and geo-located; or if they have been identified, geo-located and have a designated personal emergency plan. The second is the presence and typology of specific stakeholders (public and non-profit) in the local community, such as civil protection organizations, social services, disabled people organizations, and elderly people organizations.

\section{Disabled, Elderly and Marginal Resilience: Search Results}

\subsection{Detecting Vulnerability is Difficult}

The results of this research can be summarized as follows. Firstly, people with disabilities and the elderly are identified at the local level, but there's a lack of knowledge regarding their state of vulnerability. In the event of a natural disaster, the shortage of information is a problem for building an appropriate model of intervention. Secondly, where the information about the state of vulnerability exists, it is not integrated with the other data needed in order to understand the exact location in the territory. Thirdly, the information regarding the disabled is very detailed, considering that they have been followed by social and health services since birth, while the information regarding the elderly population is very fragmented and susceptible to sudden changes (e.g. during the transition from a situation of inclusion to one of exclusion as a result of the onset of a disease such as Alzheimer's). Fourthly, generally in communities resilience is often identified through the use of general models that do not take into account the situation of the disabled and elderly.

\subsection{Positive Role of Voluntary Organizations and Different Welfare Systems}

The research results are different for each community that was studied, but it is possible to identify the following common areas. First of all, identifying vulnerable people is not easy. Younger individuals and/or people without disabilities may be included in the databases. In this case, voluntary organizations are able to integrate public databases with other relevant information. Second, identification is sometimes rejected because the individuals do not want to be labeled as vulnerable. The role of voluntary organizations becomes relevant in order to overcome these difficulties because they build confidence through activities of proximity and relationship networks. Third, the spheres of life that are most relevant to integration in the risk management system are the state of health and social relations. A good survey of these two aspects allows for the development of a usable database in an emergency situation.

Fourth, there are differences among the communities involved in the research which are caused by the different welfare systems adopted. Denmark has a welfare system where the public is central, while in Italy the situation is similar to Klausen and completely different (private system) in Sicily. These can be overcome through intervention methods shared by voluntary organizations. The added social value of voluntary organizations of a certain size is similar in all European countries involved in the research. Therefore it is possible to imagine an intervention model based on voluntary activity to increase marginal resilience.

\section{The Added Social Value of Voluntary Organizations in the Marginal Resilience}

Figure 2 lists the twenty-one dimensions of the added social value of voluntary work called, "The Alphabet of Social Cohesion" (6). 


\section{THE ALPHABET OF SOCIAL COHESION (THE DISTINCTIVE TRAITS OF THE VOLUNTARY WORK) - The twenty one dimensions}

\author{
1) Social sostenibility \\ 2) diffused relations and the linking social capital \\ 3) the democratization and the participation \\ 4) the reproduction of relations \\ 5) frame of programming and co-projectuality \\ 6) sinergic action with public entities \\ 7) Flexibility \\ 8) Universality of access \\ 9) construction of the evaluation of quality \\ 10) the valorization of the phisical proximity
}

\author{
11) the valorisation of the territory \\ 12) the partecipative organisation \\ 13) the value of listening \\ 14) Communication \\ 15) Citizen education \\ 16) the ethic of the gratuity and of the gift \\ 17) the innovation \\ 18) the risk \\ 19) the immagination \\ 20) the development of the knowledge work \\ 21) governance
}

Figure 2. The Alphabet of Social Cohesion

Some dimensions of the Alphabet of Social Cohesion that can characterize voluntary organizations are relevant to the approach for increasing marginal resilience:

a) capability of multiplying relationships (social capital);

b) capability of building sharing through communication (7);

c) capability of simplifying and promoting the participation of their own partners and citizens as protagonists of their actions (8);

d) capability of educating active citizenship through the development of political roles;

e) capability of social and technological innovation coherent with the social cohesion of territorial communities (9); and

f) capability to activate a presence close to the people in the territories.

Does an added social value exist in voluntary work in prevention aimed at vulnerable people?

Yes, if it is managed with a non-hierarchical structure that facilitates communication and participation, is a multiplier of communicative relationships, is an innovative social use of technologies with the capability of managing complex situations, is a multiplier of linking social capital, and is close to the people in the territories because it has its roots in local communities.

In our research we were able to evaluate the size of the identified social value of voluntary organizations that are essential for increasing marginal resilience. The leading role of voluntary organizations increases the degree of social cohesion and resilience of local communities with no additional economic costs. Furthermore, their presence in the models of risk management allows for achieving a level of detail (especially with regard to the vulnerability of the elderly and the disabled) otherwise unreachable by the government or civil protection system.

\section{Conclusions}

The research work presented is intended to contribute to the realization of an intervention model for vulnerable people (the disabled and elderly) in the event of natural disasters in some European countries. Among the most relevant results of the research was the identification of the concept of marginal resilience with reference to the most vulnerable sections of the population. The growth of marginal resilience seems to be related to the presence of a higher social cohesion due, in part, to the presence of voluntary organizations with a high social value and, in part, to the attention of local communities to the vulnerability. Regardless of the crisis caused by natural disasters, an increase in marginal resilience is an important sign of the wellbeing of a local community and is to be examined more thoroughly with additional specific research and exploration.

\section{REFERENCES}

[1] Béné C., Towards a Quantifiable Measure of Resilience, IDS Working Papers no. 434, IDS, 2013.

[2] Cutter S.L., Barnes L., Berry M., Burton C., Evans E., Tate E., Webb J.A. Place-based model for understanding community resilience to natural disasters, in Global Environmental Change no. 18, 598-606, lbrr.covalentwords.com/assets/docs /33.pdf, 2008.

[3] Winderl T., Disaster resilience measurement. Stocktaking of ongoing efforts in developing systems for measuring resilience, United Nations Development Programme, 2014.

[4] Castel R., Les métamorphoses de la question sociale : une chronique du salariat, coll. Folio, Paris,éd. Gallimard, 1995.

[5] Tusini S., La ricerca come relazione. L'intervista nelle scienze sociali, Milano, Franco Angeli, 2006. 
[6] Volterrani A., Tola P., Bilotti A. Il gusto del volontariato, Roma, p. 23, Exorma Edizioni, 2009.

[7] Volterrani A., Saturare l'immaginario. Per una nuova comunicazione sociale, Roma,Exorma Edizioni, 2011.

[8] Ceccherelli A., Spinelli A., Tola P., Volterrani A. Il valore del volontariato. Indicatori extra-economici del dono, Firenze, Quaderni Cesvot n.58,cesvot.it/repository/cont_schedemm/7 853 documento.pdf,2012.

[9] Peruzzi G., Volterrani A. Daily Life of Non Profit Organisations Inhabiting the Web, in "Journal of Sociocybernetics", pp. 107-120, vol. 7, 2010. 